\title{
Application Research Progress of DSA
}

\author{
WANG LiXuan ${ }^{1, a}$, CHENG YanKun ${ }^{1, b}$, GAO YanAn ${ }^{1, a}$ \\ Hebei Chemical and Pharmaceutical Vocational College, Hebei Shijiazhuang,050026 \\ a3491832@qq.com, b1247360413@qq.com, a3491832@qq.com,
}

Key words: DSA, electroplating, electrolysis, wastewater treatment

Abstract: The dimensionally stable anode get more usage in electroplating and wastewater treatment industry, because it's stable size, low operation voltage, less energy consumption, high electro-catalytic activity, and not having secondary pollution. It can form clean technologies and gradually replace lead and graphite pole.

\section{Introduction}

Titanium coated electrode is created by H Beer in 1968, which is named DSA (dimensionally stable anode). This electrode is the main form of metallic oxide. The distance between anode and cathode will not change, so its electrode wear is small and the size is stable. Titanium coated electrode has been widely used in electrolysis industry because of its property, which brings lots advantages.

DSA should be a way for electro-catalytic electrode, which doesn't have the shortage of graphite, platinum, lead alloy and pbo_2 electrode. The interelectrode distance of DSA doesn't change during electrolysis and the size of anode is stable, comparing graphite and lead alloy electrode. It can ensure the operation of electrolysis in cell voltage is stable. DC consumption could decrease $10 \%$ to $20 \%$ because of its low voltage and small power consumption. Titanium anode with long service life and good corrosion resistance can solve the problem of dissolution of graphite anode and lead anode, which could avoid polluting the electrolyte and products.DSA can also avoid short circuit after the deformation of lead anode, which can improve the efficiency of electricity.

\section{The Application of DSA}

The Application of DSA in Electroplate

DSA's technology of electrochemical reaction is mature as an insoluble anode. Currently, insoluble anode is most extensive used most extensive in chlor-alkali industry. Make chlorine and caustic by electrolysis of salt liquor. Chlorine evolution is the main reaction at the positive pole, meanwhile the secondary reaction is oxygen evolution. Chlorine evolution potential can be significantly reduced by DSA, and bubbles of chlorine can digress easily. More than $1 \times 105 \mathrm{~m} 2$ titanium electrode has been used in chlor-alkali industry by 1980s in Japan.

Betilleheml Inland Prefinish Metals Company use titanium anode produce galvanized steel sheets by 20 upright plating tanks, what electric current is $50 \mathrm{Ka}$ and speed is $210 \mathrm{~m} / \mathrm{min}$, instead of lead anode. The plating of electrogalvanizing is the alloy of $\mathrm{Zn}$ and $\mathrm{ZnNi}$. Its effect is good.

German company, SalmaxGm was set up in 1987. Its production is NO.1 electrogalvanizing, which has 6 upright plating tanks, what productivity is $0.1 \mathrm{Mt} / \mathrm{a}$ and the speed is $210 \mathrm{~m} / \mathrm{min}$. It uses insoluble anode to reduce energy-consumption of electroplating and increase the density of plating current, which create condition for producing thick electrogalvanizing plate. 


\section{The Application of DSA in Electrolysis}

DSA is also widely used in electrolysis. Use DSA as the anode, insoluble anode plays the role of location and basal during electrolysis, such as separating out oxygen at $\mathrm{Pb}-\mathrm{Ag}$ anode. Treat $\mathrm{Pb}-\mathrm{Ag}$ anode as the catalyst or electro-catalyst of the charge transfer reactions, while it doesn't have the effect of increasing the electrode reaction.DSA is an insoluble anode, what base martial is stainless steel, admire and so on. Catalytic noble metal oxides are covered base martial. Electric field of electrode interface has great influence to the reaction speed because of the electrocatalysis of noble metal oxides. The reaction speed can increase 10 five orders of magnitude as the increase of overpotential during electrode reaction.DSA has high energy conversion efficiency, because it can get lower overpotential as insoluble anode.

Jin Rongtao uses DSA, which is covered noble metal oxides, in the production of electrolytic copper foil. Oxygen has low overpotential, long life span and non-pollution. Comparing to normal $\mathrm{Pb}-\mathrm{Ag}$ anode, it can decrease cell voltage more than $1.0 \mathrm{~V}$ and save energy.

Feng Bocheng uses DSA as positive pole and cadmium or lead as negative pole whiles the electrochemical synthesis of adiponitrile in the diaphragmless electrolytic cell. The electrochemical synthesis of AND processes 48 hours when $\mathrm{AN}$ is $5 \%, \mathrm{pH}$ is $6.5, \mathrm{j}$ is $2000 \mathrm{~A} / \mathrm{m}, \mathrm{v}$ is $1 \mathrm{~m} / \mathrm{s}$ and temperature is $50^{\circ} \mathrm{C}$. The productivity of adiponitrile is $85.7 \%$ and total current efficiency is $86.6 \%$ in DSA-Cd cell, while the productivity of adiponitrile is $80.1 \%$ and total current efficiency is $77.7 \%$ in $\mathrm{DSA}-\mathrm{Pb}$ cell. It proves that DSA is good electrode material for the electrochemical synthesis of adiponitrile.

The Application of DSA in Wastewater Treatment

DSA, used as main electrolysis method, has been widely developed in the process of high-concentration and refractory salinity wastewater in recent years. Electrochemical oxidation technology is adopted in treating wastewater, which can change the nature and structure of organic pollutant. It's one of the important field for environmental protection's developing, because it's easy management operations, stable quality of output water, well decolorization effect, small usage of land and strong biodegradability.

Wei Yanjun, etc use DSA bleach and clean mixed juice by electrolysis. It proves that electrolysis by DSA can clean the hydroxybenzene in wastewater, decrease the effect to the change of sugar and disintegrating of reducing sugar. The electrolysis of mixed juice processes under $0-20 \mathrm{~V}$ voltage. It can bleach easily when the current density is $167-400 \mathrm{~A} / \mathrm{m} 2$, and the decolorization rate can reach $70 \%$. Considering the Power consumption, the result of mixed juice's electrolysis is the best when the current density is $167 \mathrm{~A} / \mathrm{m} 2$ and potential gradient is $15 \mathrm{~V} / \mathrm{cm}$ in the same condition. The decolorization rate increases along with the time passing by during $0 \mathrm{~min}$ to $40 \mathrm{~min}$, while it is almost stable after $40 \mathrm{~min}$. the increasing of electrolysis time can lead to the increase of power consumption.

Lu Qiang, etc use DSA with interlayer catalyze wastewater of nitrobenzene. Making the interlayer, first should prepare a certain $\mathrm{SnCl} 4$ and $\mathrm{SbCl} 3$ alcoholic solution, then brush this solution on titanium substrate surface, heat in the muffle in $500^{\circ} \mathrm{C}$ for $10 \mathrm{~min}$ after drying in $100^{\circ} \mathrm{C}$. Repeat 3 to 5 times and sintering for 40min the last time. After making interlayer, preparing a certain $\mathrm{SnCl} 4$ and $\mathrm{SbCl} 3$ alcoholic solution and brushing on the surface of interlayer, drying it under $100^{\circ} \mathrm{C}$, heating in muffle in $450^{\circ} \mathrm{C}$ for $15 \mathrm{~min}$ and then cool to ambient temperature. Repeat 15 to 18 times and sintering for $60 \mathrm{~min}$ the last time. Use this electrode treat nitrobenzene wastewater after the make of interlayer and skin layer. It discovers that it's easy to clean the pollution when the plate distance 
decreasing in current density of $20 \mathrm{~mA} / \mathrm{cm} 2$ and $\mathrm{Na} 2 \mathrm{SO} 4$ of $10 \mathrm{~g} / \mathrm{L}$. Meanwhile it's easy to clean nitrobenzene when the $\mathrm{PH}$ is 5.

Li Wenwu, etc use self-made DSA treat flax wastewater. The electrode is Ce with dopant of $\mathrm{RuO} 2 / \mathrm{Ti}$ and $\beta-\mathrm{PbO} 2 / \mathrm{Ti}$. In the experiment two self-made electrodes are used. The electrode area is $12 \mathrm{~cm} 2$, the plate distance is $2 \mathrm{~cm}$, the quality of flax wastewater is $100 \mathrm{~g}, \mathrm{C} / \mathrm{Ru}(\omega \mathrm{Ru}=0.5 \%)$ is $10 \mathrm{~g}$, cell voltage is $10 \mathrm{~V}$ and the time of electrolysis is $2 \mathrm{~h}$ in the flax wastewater. Change DSA after filtering. The removal rate of CODCr reaches $68.8 \%$ under $10 \mathrm{~V}$ voltage and 2 hours' electrolysis.

Tian Jianhui, etc use USA treat acidic scarlet-3R wastewater by the technology of electricity and three-dimensional electrode. The removal rate of CODCr approaches $80 \%$ and the colority removal rate reaches $95 \%$ after 8hours' electrolysis in $3.2 \mathrm{~L} / \mathrm{min}$ flow velocity and $100 \mathrm{~mA} / \mathrm{cm} 2$ current density. It proves that the organic in wastewater is degraded, so good benefits in environment and economy have been obtained.

\section{Conclusion}

DSA is widely used in the area of electroplating, electrolysis and wastewater treatment. Electrode has an important function in electrochemical reaction, which has great influence to the reaction speed and reaction mechanism. Meanwhile, electrode material has important influence to many parameters, like momentum point during electrochemical reaction. DSA plate, which has long lifespan and no secondary pollution, can replace anode plate, which has big volume and heavy weight. It has other properties, like easy to process many shapes, higher catalytic property and reusing substrate material. In conclusion, DSA has wide application prospect in electrochemical reaction.

\section{References}

[1]Zhang Zhaoxian.2004.Research and application of titanium coated electrode.Rare Metal Expre23(4):1-7

[2]Zhou Qiliang.1992.Foreign metal materials.1:25-32

[3]Fu Hangguang, YaoShudian, Wu Jianzhong.1996.Development on the application of titanium anode for steel strip electroganizing.Shanghai Metals18(2):9-12

[4]Jin Rongtao.1998.Application of DSA in the production of electrolytic copper foil.Nonferrous Smelting 5:27-28

[5]FengBaicheng,GuanXianwen, Wang Guangxin.2010.Application of dimensionally stable anodes in electro-synthesis of adiponitrile. CIESCJournal61(S1):68-71

[6]WeiYanjun,Chen Shan, Zou Qingsong.2009.Study on Electrolytic Decolourization and the Changes during the Processing of the Mixed Juice with the Electrode of DSA.Sugarcane and Canesugar6:23-28

[7]LuQiang,Anlichao, Wangzhiliang,etl.2009.Study on degradation of nitrobenzene wastewater by electrocatalytic oxidation eith DSAelectrode. Chinese Journal of Environmental Engineering3(11):1189-1194 
[8]LiuWenwu,Tu xueyan,WanagWei,etl.2007.Preparation and evaluation on the electrocatalyticcharacheristcs of two kinds of DSA electrodes.Environmental Chemistry26(2):152-156

[9]TianJianhui,MaHongrui.2012.Paired electrooxidation for dye wastewater electro-oxiidation using three-dimensional electrodes. Technology of water treatment38(3):114-117 